\title{
Surface exposure and protease insensitivity of Borrelia burgdorferi Erp (OspEF-related) lipoproteins
}

\author{
Nazira El-Hage, ${ }^{1}$ Kelly Babb, ${ }^{1}$ James A. Carroll, ${ }^{2}$ Nicole Lindstrom, ${ }^{2} \dagger$ \\ Elizabeth R. Fischer, ${ }^{2}$ Jennifer C. Miller, ${ }^{1}$ Robert D. Gilmore, Jr, ${ }^{3}$ \\ M. Lamine Mbow $^{4} \ddagger$ and Brian Stevenson ${ }^{1}$
}

Author for correspondence: Brian Stevenson. Tel: +1 859257 9358. Fax: +1 8592578994. e-mail: bstev0@pop.uky.edu

\footnotetext{
1 Department of Microbiology and Immunology, University of Kentucky College of Medicine, MS 415 Chandler Medical Center, Lexington, KY 40536-0298, USA

2 Microscopy Branch, Rocky Mountain Laboratories, NIAID, National Institutes of Health, 903 South 4th St, Hamilton, MT 59840, USA

3 Division of Vector-Borne Infectious Diseases, National Center for Infectious Diseases, Centers for Disease Control and Prevention, $\mathrm{PO}$ Box 2087, Foothills Campus, Fort Collins, CO 80522, USA

4 Department of Pathology, College of Veterinary Medicine and Biomedical Sciences, Colorado State University, Fort Collins, CO 80523-1671, USA
}

\begin{abstract}
Borrelia burgdorferi can encode numerous lipoproteins of the Erp family. Although initially described as outer surface proteins, the technique used in that earlier study has since been demonstrated to disrupt bacterial membranes and allow labelling of subsurface proteins. Data are now presented from additional analyses indicating that Erp proteins are indeed surface exposed in the outer membrane. Surface localization of these infection-associated proteins indicates the potential for interactions of Erp proteins with vertebrate tissues. Some Erp proteins were resistant to in situ digestion by certain proteases, suggesting that those proteins fold in manners which hide protease cleavage sites, or that they interact with other protective membrane components. Additionally, cultivation of B. burgdorferi in the presence of antibodies directed against Erp proteins inhibited bacterial growth.
\end{abstract}

Keywords: spirochaete, immunofluourescence, Erp proteins, bacterial surface proteins, protease resistance, Lyme disease

\section{INTRODUCTION}

The causative agent of Lyme disease, the spirochaete Borrelia burgdorferi, has evolved mechanisms enabling infection of both warm-blooded and arthropod hosts, and permitting efficient transmission between these two very different types of hosts. When a tick feeds on an infected vertebrate, ingested spirochaetes colonize the tick's midgut and persist in that organ until the tick feeds again. After the tick attaches to another vertebrate host

\footnotetext{
†Present address: Dept. of Molecular Biology, University of Wyoming, Laramie, WY 82071, USA.

¥Present address: Centocor Inc., 200 Great Valley Parkway, Malvern, PA 19355, USA.

Abbreviation: IFA, immunofluorescent antibody.
}

and begins feeding, the B. burgdorferi penetrate the tick midgut wall, migrate through the haemolymph to the salivary glands and are transmitted to the vertebrate via the tick's saliva. Upon entering the new, warmblooded, host, the bacteria presumably interact with the vertebrate's tissues to facilitate dissemination throughout its body (Schwan et al., 1999). The different environments encountered by B. burgdorferi during this complex infectious cycle undoubtedly require that the bacteria sense their location and synthesize proteins appropriate for that time and place. Since proteins that interact with host tissues will most likely be located on the outer surface of the bacteria, identification of surface-exposed $B$. burgdorferi proteins can lead to increased understanding of the mechanisms underlying the ability of these bacteria to infect humans and other animals. In addition, surface proteins synthesized during 
mammalian infection are potential candidates for vaccines to prevent Lyme disease.

B. burgdorferi contains many lipoproteins, and early studies of these and other spirochaetes utilized a variety of methods to study lipoprotein localization (Barbour et al., 1983a; Bledsoe et al., 1994; Cunningham et al., 1988; Fuchs et al., 1992; Jones et al., 1995; Lam et al., 1994; Luft et al., 1989; Radolf, 1994; Radolf et al., 1995). More recently, it has become apparent that outer membranes of many spirochaetes, including $B$. burgdorferi, are relatively fragile, and some previously utilized techniques may yield inaccurate results (Cox et al., 1996). Re-evaluation of spirochaetal membrane proteins indicated that some lipoproteins initially described as 'outer surface proteins' appear to be primarily located in the inner membrane and/or inner leaflet of the outer membrane (Bledsoe et al., 1994; Brusca et al., 1991; Cox et al., 1996; Radolf, 1994; Radolf et al., 1994). It is important, then, that proteins designated as surface exposed by potentially flawed methods be examined further by other techniques (Haake, 2000).

All Lyme disease spirochaetes that have been examined contain large numbers of genes encoding members of the Erp protein family, encoded on multiple, homologous circular and linear plasmids (the cp32 family of plasmids). These proteins apparently perform functions that are unique to the infectious cycle of Lyme disease spirochaetes, since erp genes have not been identified in any other bacteria of the genus Borrelia (Stevenson et al., 2000a). All erp genes hold several features in common, including well-conserved promoter DNA sequences, locations on a family of homologous plasmids and the encoding of highly charged lipoproteins with well conserved leader polypeptides (reviewed by Stevenson et al., 2000b). Those Erp proteins examined were all found to be lipidated by bacteria (Akins et al., 1995; Lam et al., 1994; Wallich et al., 1995). Laboratory animals infected by tick bites generally produce antibodies against Erp proteins within the first 2-4 weeks of infection (Akins et al., 1995; Das et al., 1997; Nguyen et al., 1994; Stevenson et al., 1998a; Suk et al., 1995; Sung et al., 2000; Wallich et al., 1995), suggesting that Erp proteins play roles in the initial stages of mammalian infection. Reverse transcriptasePCR studies have also demonstrated erp expression during this time period (Anguita et al., 2000; Das et al., 1997), as have analyses of bacteria grown in chambers implanted within the bodies of laboratory animals (Akins et al., 1998). To date, 17 erp genes at 10 loci have been identified in B. burgdorferi strain B31. The coding regions of three bicistronic loci, erp $A B$, erpIJ and $\operatorname{erpNO}$, are identical, so their protein products are indistinguishable and are referred to collectively as ErpA/I/N and ErpB/J/O. The other seven B31 loci encode Erp proteins with varying degrees of dissimilarity (Casjens et al., 1997, 2000; Stevenson et al., 1998a, b). It is assumed that the variations among Erp protein sequences confer some advantage to the bacteria, but the nature of that benefit remains to be elucidated (El-Hage et al., 1999; Stevenson et al., 2000b; Sung et al., 2000).
The lipid moiety of Erp lipoproteins anchors them to a membrane, but prior to the current study it was not known with confidence to which membrane(s) or to which leaflet(s) the Erps are attached. One previous study examined the cellular localization of two proteins of the Erp family, the OspE and OspF proteins of strain N40, using immunofluorescent antibody (IFA) analyses of bacteria fixed with formaldehyde (Lam et al., 1994). While that study detected antibody binding to the fixed bacteria, suggestive of surface exposure, it has since been observed that fixation can disrupt the outer membrane, allowing subsurface proteins to bind antibodies (Cox et al., 1996). Additionally, the polyclonal antisera used in the earlier study contain antibodies that recognize other proteins besides OspE and OspF (Marconi et al., 1996; Stevenson et al., 1995), so it is possible that the proteins detected by those IFA analyses were neither OspE nor OspF. Other studies demonstrated that vaccination with some recombinant Erp proteins provided partial protection against $B$. burgdorferi infection, suggestive of exposure to the external environment, yet vaccination with other Erp proteins failed to protect against infection, arguing against surface localization (Nguyen et al., 1994; Wallich et al., 1995). Since the cellular location of the $B$. burgdorferi Erp proteins was unclear, we examined these proteins through a variety of independent techniques. Together, these data indicate that Erp proteins are exposed to the external environment in the $B$. burgdorferi outer membrane and can therefore facilitate interactions between these bacteria and their hosts.

\section{METHODS}

Bacteria and culture conditions. B. burgdorferi strain B31 was originally isolated from a tick collected on Shelter Island, NY, USA, and cloned by limiting dilution (Barbour et al., 1983b; Burgdorfer et al., 1982). The B31 culture used in these studies is infectious to both mice and ticks (Schwan et al., 1995). These bacteria harbour all known B31 cp32 plasmid family members except cp32-2, and thus encode all known B31 Erp proteins except ErpC and ErpD (Casjens et al., 1997, 2000; Miller et al., 2000a; Stevenson et al., 1998a). Two alleles of $\operatorname{erp} B$ have been identified in different cultures of strain B31: $\operatorname{erpB1}$, which contains a premature stop codon and is carried by some non-infectious bacteria (Stevenson et al., 1996), and erp B2, which encodes a much longer protein and is carried by infectious bacteria of this strain (Casjens et al., 2000; Stevenson et al., 1998a, b). Bacteria in the culture used in the present studies contain only the erpB2 allele (Stevenson et al., 1998a). As noted in the Introduction, the coding regions of the strain B31 erp AB2, erpIJ and erpNO loci are identical, and thus their proteins are indistinguishable and are collectively referred to as $\operatorname{ErpA} / \mathrm{I} / \mathrm{N}$ and $\operatorname{ErpB} / \mathrm{J} / \mathrm{O}$ to reflect this point.

In vitro temperature shift experiments were conducted as previously described (Stevenson et al., 1995), using BarbourStoener-Kelly II (BSK-II) (Barbour, 1984) medium containing $6 \%$ rabbit serum (Sigma). Bacteria used for Erp protein localization analyses were grown at $35^{\circ} \mathrm{C}$ to late-exponential phase (approx. $10^{8}$ bacteria $\mathrm{ml}^{-1}$ ) in a commercially prepared BSK formulation, BSK-H (Sigma), from lot number $38 \mathrm{H} 8425$. For an as yet undetermined reason, cultivation in this particular lot of BSK-H medium causes B. burgdorferi strain 
B31 to constitutively synthesize high levels of Erp proteins (K. Babb, N. El-Hage, J. C. Miller, J. A. Carroll and B. Stevenson, unpublished results).

Antibodies. All antibodies were generated in strict accordance with United States requirements for the experimental use of animals. Polyhistidine-tagged recombinant B31 Erp proteins were produced in Escherichia coli and purified as previously described (Miller et al., 2000b; Stevenson et al., 1998a). Polyclonal antisera were generated for the B31 ErpA/I/N, ErpB/J/O, ErpK, ErpL, ErpM and ErpX proteins by vaccinating New Zealand White rabbits with approximately $50 \mu \mathrm{g}$ purified protein in Freund's complete adjuvant, followed by booster vaccinations 2 and 4 weeks later with the same dose of protein in Freund's incomplete adjuvant. Rabbit antisera directed against the B31 ErpP, ErpQ and ErpY proteins were similarly produced by Animal Pharm Services. All rabbits were exsanguinated 2 to 4 weeks after the final boost. For some studies, nonspecific antibodies were adsorbed from polyclonal antisera by incubating serum, diluted $1: 200$ in Tris-buffered saline/Tween $20(20 \mathrm{mM}$ Tris/ $\mathrm{HCl}, \mathrm{pH} 7 \cdot 5$, $150 \mathrm{mM} \mathrm{NaCl}, 0.05 \%$ Tween 20 ), for $1 \mathrm{~h}$ at $37^{\circ} \mathrm{C}$ with lysates of E. coli expressing all other recombinant Erp proteins (Stevenson et al., 1998a). Specificities of preadsorbed antisera were assessed by immunoblotting with all purified recombinant Erps.

A panel of monoclonal antibodies (mAbs) were produced from the spleen of a mouse infected with isolate B31 via tick bite, as previously described (Gilmore \& Mbow, 1998, 1999; Mbow et al., 1999). Briefly, B. burgdorferi B31-infected Ixodes scapularis nymphal ticks were fed to repletion upon $\mathrm{Balb} / \mathrm{cByJ}$ mice, and mice were reinfested 1 month later with additional B. burgdorferi B31-infected ticks. Three weeks after tick feeding, spleen cells were fused with P3X63-Ag8.653 myeloma cells. Wells were screened by ELISA using a B31 lysate as antigen and cells from positive wells were cloned by limiting dilution. $\mathrm{mAb}$ specificities were determined by immunoblotting isolate B31 whole-cell lysates and recombinant Erp proteins. Unless otherwise stated, all mAbs used in the following experiments were undiluted hybridoma supernatants.

Two previously described $\mathrm{mAbs}$ that recognize other $B$. burgdorferi $\mathrm{B} 31$ proteins were used as experimental controls: $\mathrm{B} 5$, directed against the OspC protein (Gilmore \& Mbow, 1999; Mbow et al., 1999), and H9724, directed against the flagellar FlaB subunit (Barbour et al., 1986) (provided by Tom Schwan, Rocky Mountain Laboratories, NIH, Hamilton, MT, USA). Two antibodies directed against non-borrelial proteins were used as additional controls in growth inhibition assays: mAb 83-12-5, directed against mouse CD8 (provided by Jerold Woodward, University of Kentucky, KY, USA), and polyclonal rabbit antiserum HTV, raised against the Yersinia pestis LcrV protein (provided by Susan Straley, University of Kentucky, KY, USA).

In situ protease treatment. B. burgdorferi was grown to midexponential phase in BSK-H, pelleted by centrifugation for 10 min at 1000 r.p.m. in a Beckman GPR centrifuge with a GH3.8 swinging-bucket rotor, washed once with PBS plus $10 \mathrm{mM} \mathrm{MgCl}_{2}$ (PBS-Mg), and resuspended in the same buffer to a final concentration of $2 \times 10^{9}$ bacteria $\mathrm{ml}^{-1}$. Examination of bacterial suspensions by phase-contrast light microscopy did not indicate detectable lysis of the bacteria. Bacteria were then incubated at room temperature with a protease for $30 \mathrm{~min}, 1 \mathrm{~h}$ or $2 \mathrm{~h}$, whereupon digestion was terminated by addition of an appropriate inhibitor followed by sample boiling. One of three different proteases were used in each experiment at the following final concentrations: $40 \mu \mathrm{g}$ proteinase $\mathrm{K} \mathrm{ml}^{-1}$ (Sigma), 40 or $100 \mu \mathrm{g}$ trypsin $\mathrm{ml}^{-1}$ (Sigma) or $0.05 \mu \mathrm{g}$ Pronase $\mathrm{ml}^{-1}$ (Boehringer Mannheim). Proteinase K was inhibited by addition of PMSF to a final concentration of $1.6 \mathrm{mg} \mathrm{ml}^{-1}$. Trypsin was inhibited by the addition of PMSF and pefabloc SC (Boehringer Mannheim) to final concentrations of $1.6 \mathrm{mg} \mathrm{ml}^{-1}$ and $0.3 \mathrm{mg} \mathrm{ml}^{-1}$, respectively. Pronase was inhibited by addition of PMSF, pefabloc SC and EDTA to final concentrations of $0.06 \mathrm{mg} \mathrm{ml}^{-1}, 0.3 \mathrm{mg} \mathrm{ml}^{-1}$ and $0.5 \mathrm{mg} \mathrm{ml}^{-1}$, respectively. Control aliquots of bacteria were incubated in buffer for $2 \mathrm{~h}$ at room temperature without added protease, followed by addition of inhibitor and boiling as with protease-treated bacteria. Equal volumes of bacterial lysates were subjected to SDS-PAGE and the proteins transferred to nitrocellulose membranes. Susceptibility of individual proteins to protease digestion was assessed by immunoblotting with appropriate monoclonal or polyclonal antibodies, followed by incubation with protein A-horseradish peroxidase conjugate (Amersham) and bound antibodies visualized by enhanced chemiluminescence (Amersham) (Miller et al., 2000 b). As experimental controls, lysates were also immunoblotted with mAbs directed against OspC [(located on the bacterial outer surface and thus susceptible to proteolysis (Fuchs et al., 1992; Mathiesen et al., 1998; Wilske et al., 1993)] and FlaB [located in the periplasmic space and thus protected against protease digestion in intact bacteria (Bono et al., 1998; Bunikis \& Barbour, 1999; Holt, 1978)].

Additional control experiments were performed to assess the protease susceptibility of proteins when not in situ. Bacteria were treated with proteases as above, but with the addition of Triton X-100 to a final concentration of $0 \cdot 1 \%$, which generally disrupts B. burgdorferi outer membranes (Cox et al., 1996), and lysates were immunoblotted with Erp- and FlaB-directed antibodies. Purified recombinant Erp proteins were incubated for $30 \mathrm{~min}$ in either of the three proteases and immunoblotted with an appropriate antibody.

Immunofluorescence analysis of intact $\boldsymbol{B}$. burgdorferi. One millilitre of a mid-exponential phase culture, grown in BSK-H, was placed on a Biocoat poly-D-lysine-coated $12 \mathrm{~mm}$ round cover slip (Becton Dickinson) in the well of a 24-well culture plate (Bunikis \& Barbour, 1999; Cox et al., 1996). Bacteria were gently pelleted onto the cover slip by centrifugation for $10 \mathrm{~min}$ at $200 \mathrm{~g}$ in a Beckman GPC centrifuge holding a GH3.8 swinging-bucket rotor. Slides were then washed twice with PBS. Bacteria were incubated in $500 \mu \mathrm{l}$ PBS containing $10 \%$ heat inactivated fetal bovine serum (Life Technologies) and $1 \%$ mouse serum (Sigma) for $1 \mathrm{~h}$ at room temperature. Cells were then washed with PBS, incubated overnight with $200 \mu \mathrm{l}$ mAb B11 (anti-ErpA/I/N), B5 (anti-OspC) or H9724 (anti$\mathrm{FlaB})$, followed by incubation for $2 \mathrm{~h}$ with goat anti-mouse IgG-Oregon green conjugate (Molecular Probes) in PBS containing $1 \%$ mouse serum. The coverslips were washed with PBS, mounted to slides and viewed by epifluorescence microscopy. As controls for possible interactions with the secondary antibody, bacteria were also treated as above except without incubation with a primary antibody.

Electron microscopy. Samples were washed in Hank's Balanced Salt Solution (HBSS) (Life Technologies) and $5 \mu \mathrm{l}$ droplets were allowed to adhere to carbon/collodion-coated nickel grids for $60 \mathrm{~min}$ at room temperature. The samples were blocked with $3 \%$ BSA in HBSS for 30 min prior to a 60 min incubation with either mAb B11 (anti-ErpA/I/N) or H9724 (anti-FlaB). After washing with the blocking agent, the samples were labelled with a secondary gold-conjugated antibody (Ted Pella) for $60 \mathrm{~min}$, Cells were washed, fixed with 
$2.5 \%$ glutaraldehyde and stained with $1 \%$ ammonium molybdate prior to being viewed at $80 \mathrm{kV}$ on a Hitachi 7500 transmission electron microscope.

Growth inhibition by antibodies. B. burgdorferi were grown in BSK-H to mid-exponential phase (approx. $10^{7}$ bacteria $\mathrm{ml}^{-1}$ ) and $100 \mu \mathrm{l}$ aliquots were placed in each well of a 96-well tissue culture dish (Becton Dickinson). One hundred microlitres of each polyclonal rabbit antiserum or $\mathrm{mAb}$ hybridoma supernatant, either undiluted or serially diluted in BSK-H, was added to the bacterial cultures. Plates were covered with Breathe-Easy gas-permeable adhesive seals (Diversified Biotech) (Bono et al., 2000) and incubated at $37^{\circ} \mathrm{C}$ in a $5 \% \mathrm{CO}_{2}$ environment. After $72 \mathrm{~h}$, growth was monitored visually for colour changes in the medium's phenol red indicator, since a change from red to yellow indicates acidification due to bacterial growth (Sadziene et al., 1993). Culture aliquots were also examined at that time by phase-contrast light microscopy for absence of bacterial motility and the formation of immobile bacterial aggregates (Bunikis \& Barbour, 1999; Cinco, 1992; Coleman et al., 1992; Hanson et al., 1998; Luke et al., 2000; Pavia et al., 1991; Sadziene et al., 1993).

As controls, bacteria were also cultivated as above with the OspC-directed mAb B5, the FlaB-directed mAb H9724, nonborrelial mAb 83-12-5, hybridoma culture medium, nonborrelial polyclonal rabbit antiserum HTV, normal rabbit serum (all undiluted) or BSK-H without any additions.

\section{RESULTS}

\section{Production of Erp-specific antibodies}

Previously, a panel of five mAbs was generated from mice that had been infected with $B$. burgdorferi $\mathrm{B} 31$ via tick bite. One of these mAbs was directed against the OspC surface protein (Gilmore \& Mbow, 1999; Mbow et al., 1999). Two others recognized the Rev protein (Gilmore \& Mbow, 1998, and our unpublished results), an uncharacterized $17 \mathrm{kDa}$ protein encoded by a pair of identical genes, one each on the B31 cp32-1 and cp32-6 plasmids (Casjens et al., 2000). The two remaining $\mathrm{mAbs}, \mathrm{B} 11$ and B31.100, both specifically recognized B31 proteins with approximate molecular masses of $19 \mathrm{kDa}$. We and others have previously reported that a

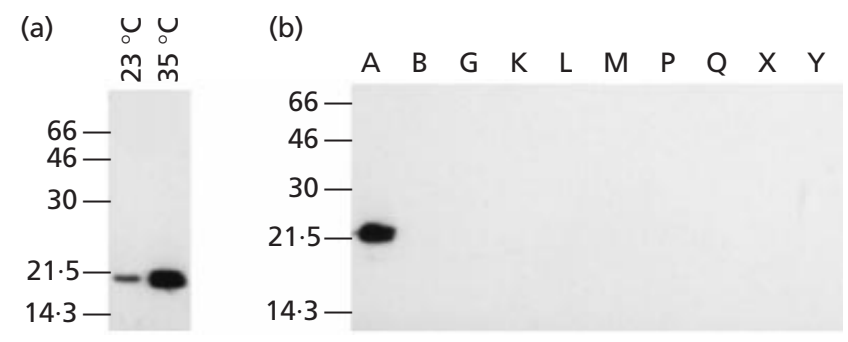

Fig. 1. Specificity of $m A b B 11$ for ErpA/I/N. (a) Immunoblot of bacteria cultured at $23{ }^{\circ} \mathrm{C}$ or shifted from 23 to $35^{\circ} \mathrm{C}$ (labelled $23^{\circ} \mathrm{C}$ and $35^{\circ} \mathrm{C}$, respectively). Note that this mAb recognizes only a single protein in the bacterial lysates. (b) Immunoblot of recombinant B31 Erp proteins ErpA/I/N, ErpB/J/O, ErpG, ErpK, ErpL, ErpM, ErpP, ErpQ, ErpX and ErpY (labelled A, B, G, K, L, $\mathrm{M}, \mathrm{P}, \mathrm{Q}, \mathrm{X}$ and $\mathrm{Y}$, respectively). As previously described (Stevenson et al., 1998a), native and recombinant ErpA/I/N exhibit different electrophoretic mobilities. small number of $B$. burgdorferi proteins, including the Erp proteins, are produced at low levels by bacteria cultured at $23{ }^{\circ} \mathrm{C}$ but are made at significantly higher levels following a shift from 23 to $35^{\circ} \mathrm{C}$, a temperature change that mimics that experienced by the bacteria within a tick vector before and during feeding on a warm blooded animal (air and blood temperatures, respectively) (Akins et al., 1998; Schwan et al., 1995; Stevenson et al., 1995, 1998a). Since both the B11 and B31.100 mAbs recognized antigens of sizes similar to some strain B31 Erp proteins, lysates of strain B31 grown at $23{ }^{\circ} \mathrm{C}$ or shifted from 23 to $35^{\circ} \mathrm{C}$, as well as recombinant Erp proteins, were immunoblotted with these hybridoma supernatants. These studies revealed that both the B11 and B31.100 mAbs recognized ErpA/I/N and no other protein produced by the B31 culture used in the present studies (Fig. 1 and data not shown). The nature by which these mAbs were produced is additional evidence that $B$. burgdorferi synthesize ErpA/I/N during mammalian infection (Stevenson et al., 1998a). Significantly, for the studies described below, the specificities of these two antibodies enabled analysis of $\mathrm{ErpA} / \mathrm{I} / \mathrm{N}$ in intact bacteria without the complications of cross-reactivity often found with polyclonal antiserum (Lam et al., 1994; Marconi et al., 1996; Stevenson et al., 1995).

Polyclonal antisera were also generated by vaccination of rabbits with recombinant B31 Erp proteins. Since B31 Erps can share significant amino acid sequence identities (Stevenson et al., 1998b), some antisera contained antibodies that also recognized other Erp proteins. For example, antisera from rabbits vaccinated with recombinant ErpB/J/O also bound the similar ErpM, ErpQ and ErpX proteins (data not shown). Preincubation of diluted antisera with non-targeted recombinant Erp proteins was found to adsorb all detectable crossreactive antibodies. Such sera were used to confirm that proteins detected by the immunoblotting studies described below were indeed the Erp proteins in question. These sera also confirmed that strain B31 synthesizes the newly described ErpP, ErpQ and ErpY proteins (Casjens et al., 2000) in vitro and that their synthesis is regulated by culture temperature shift in manners similar to the other, previously described B31 Erps (data not shown).

\section{Protease sensitivity of Erp proteins in situ}

Protein surface exposure was first examined by incubation of intact bacteria with proteases, on the premise that exposed proteins will be degraded, while subsurface proteins are protected against proteolysis. Three different proteases were used in these studies, since some B. burgdorferi surface proteins are known to be resistant to certain enzymes (Bunikis \& Barbour, 1999; Dunn et al., 1990; Zückert et al., 2001). Some B31 Erp proteins, such as ErpA/I/N, were completely degraded after short exposure times to all examined proteases, indicative of exposure to the external environment (Fig. 2, Table 1). The known outer surface protein OspC was also degraded by protease (Fuchs et al., 1992; Mathiesen et al., 1998; Wilske et al., 1993). On 


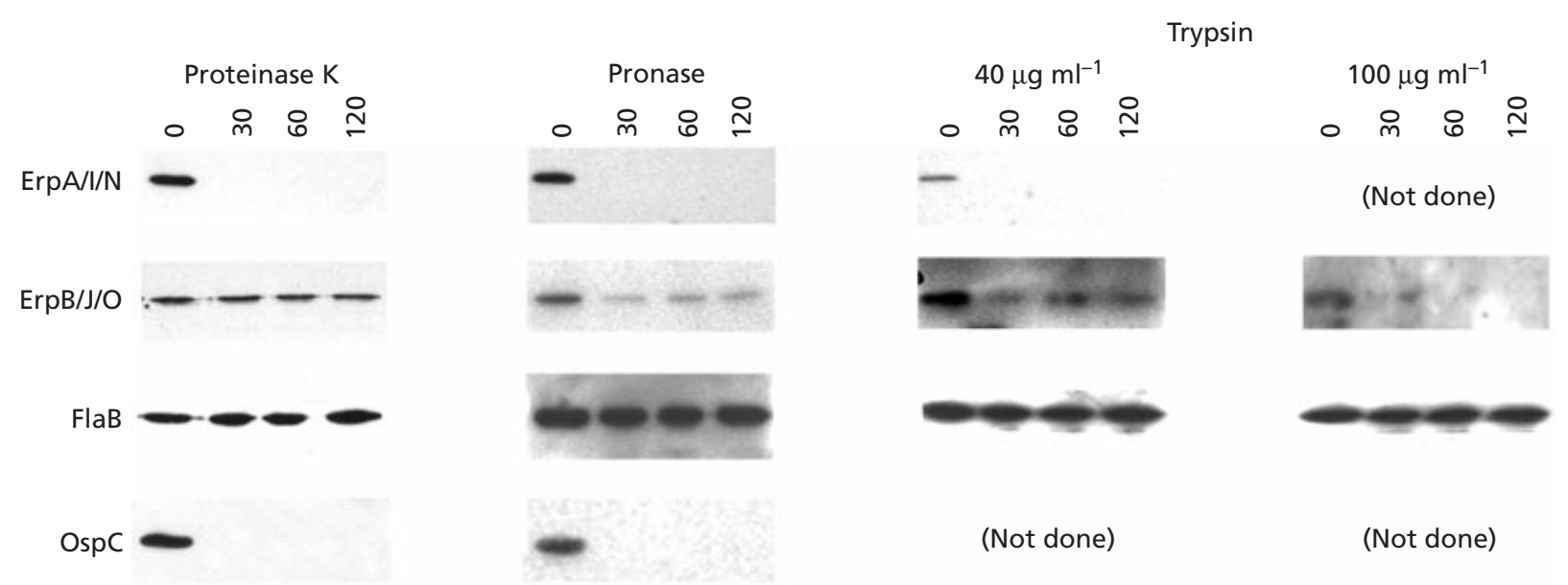

Fig. 2. Representative immunoblots of in situ protease treated $B$. burgdorferi. Bacteria were incubated with either proteinase $\mathrm{K}$, Pronase or trypsin (at 40 or $100 \mu \mathrm{g} \mathrm{ml}^{-1}$ ) for either 30,60 or $120 \mathrm{~min}$, or in buffer without any protease (labelled 0).

Table 1. Susceptibility of proteins to protease digestion in intact bacteria

Lysates of bacteria that had been incubated with proteases were immunoblotted with each antibody and scored for complete protein digestion $(+)$, digestion of only some protein molecules $( \pm)$ or no detectable digestion $(-)$. ND, Not done.

\begin{tabular}{|lcccc|}
\hline \multirow{2}{*}{ Protein } & Proteinase K & Pronase & \multicolumn{2}{c|}{ Trypsin $\left(\mu \mathrm{g} \mathrm{ml}^{-1}\right)$} \\
\cline { 3 - 5 } & & & 40 & 100 \\
\hline ErpA/I/N & + & + & + & ND \\
ErpB/J/O & - & \pm & \pm & + \\
ErpK & - & \pm & ND & ND \\
ErpL & + & ND & ND & ND \\
ErpM & - & \pm & \pm & + \\
ErpP & + & + & + & ND \\
ErpQ & \pm & \pm & \pm & + \\
ErpX & - & \pm & \pm & \pm \\
ErpY & + & ND & ND & ND \\
OspC & + & ND & ND & ND \\
FlaB & - & - & - & - \\
\hline
\end{tabular}

the other hand, some proteins, such as $\mathrm{ErpB} / \mathrm{J} / \mathrm{O}$, were not detectably degraded by proteinase $\mathrm{K}$ and only a portion of the molecules were digested by Pronase or $40 \mu \mathrm{g}$ trypsin $\mathrm{ml}^{-1}$. Complete degradation of $\mathrm{ErpB} / \mathrm{J} / \mathrm{O}$ was only observed after $60 \mathrm{~min}$ incubation with $100 \mu \mathrm{g}$ trypsin $\mathrm{ml}^{-1}$ (Fig. 2). Even a $2 \mathrm{~h}$ incubation with the highest tested concentration of trypsin did not completely digest all ErpX molecules, although some proteolysis was apparent (Table 1). The bacterial outer membranes remained intact during all in situ proteolysis treatments, since there was no detectable degradation of FlaB, a component of the periplasmic flagella (Fig. 2). We conclude that all tested B31 Erp proteins are exposed to the environment and that some are resistant to degradation by certain proteases.

Additional experiments demonstrated that protease insensitivity of Erp proteins was not solely a consequence of amino acid composition. Incubation of cells with proteases in buffer containing $0 \cdot 1 \%$ Triton X-100, which generally disrupts $B$. burgdorferi outer membranes (Cox et al., 1996), resulted in complete digestion of all tested Erp proteins. FlaB was also completely degraded by proteases under these conditions. Furthermore, purified recombinant Erp proteins were completely digested after 30 min incubations with each of the examined proteases (data not shown).

\section{IFA analysis and immunogold labelling of unfixed bacteria}

Since fixation can disrupt B. burgdorferi membranes, unfixed bacteria were used for IFA studies to further assess Erp surface exposure. We observed that greater than $70 \%$ of examined bacteria bound ErpA/I/Nspecific $\mathrm{mAb} B 11$, again indicating that this Erp protein is exposed on the outer surface of B. burgdorferi (Fig. 3). Bacteria did not fluoresce uniformly, but instead exhibited a punctate pattern, suggesting localization of ErpA/I/N at certain points along the bacterial cell. However, since B. burgdorferi B31 does not produce quantities of ErpA/I/N sufficient to be visualized by Coomassie brilliant blue staining of cell lysates (Stevenson et al., 1995), the punctuate fluorescence pattern may simply be a consequence of low ErpA/I/N protein concentration. This may also be the reason why we did not observe fluorescence from all of the bacteria. Alternatively, since membrane proteins are generally free to move laterally in the membrane, this pattern may have been due to aggregation of proteins by the antibodies (Barbour \& Hayes, 1986; Barbour et al., 1983a). Less than $1 \%$ of bacteria incubated with the 


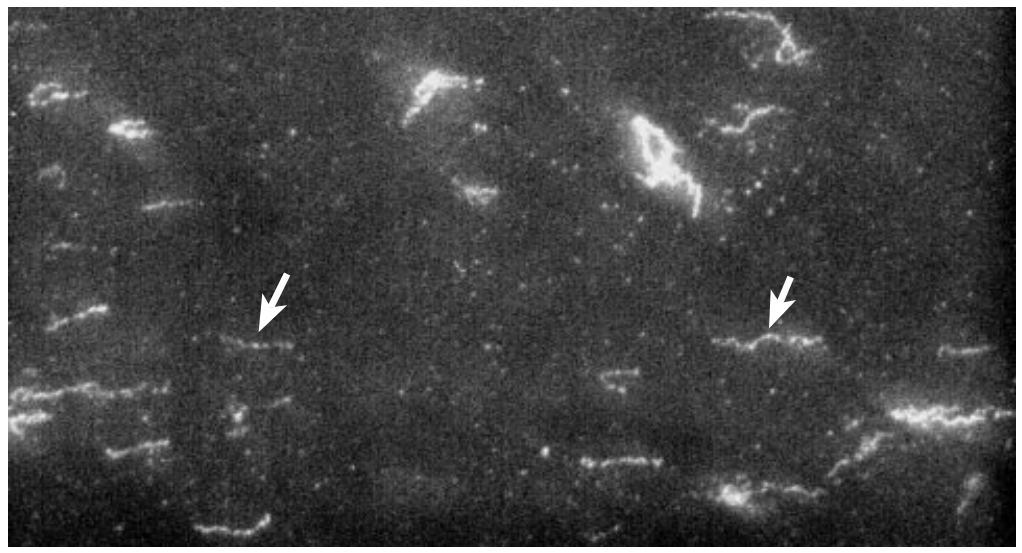

Fig. 3. Immunofluorescence analysis of unfixed $B$. burgdorferi with ErpA/l/N-specific mAb B11. The majority of bacteria did not label uniformly; two examples are indicated by arrows.
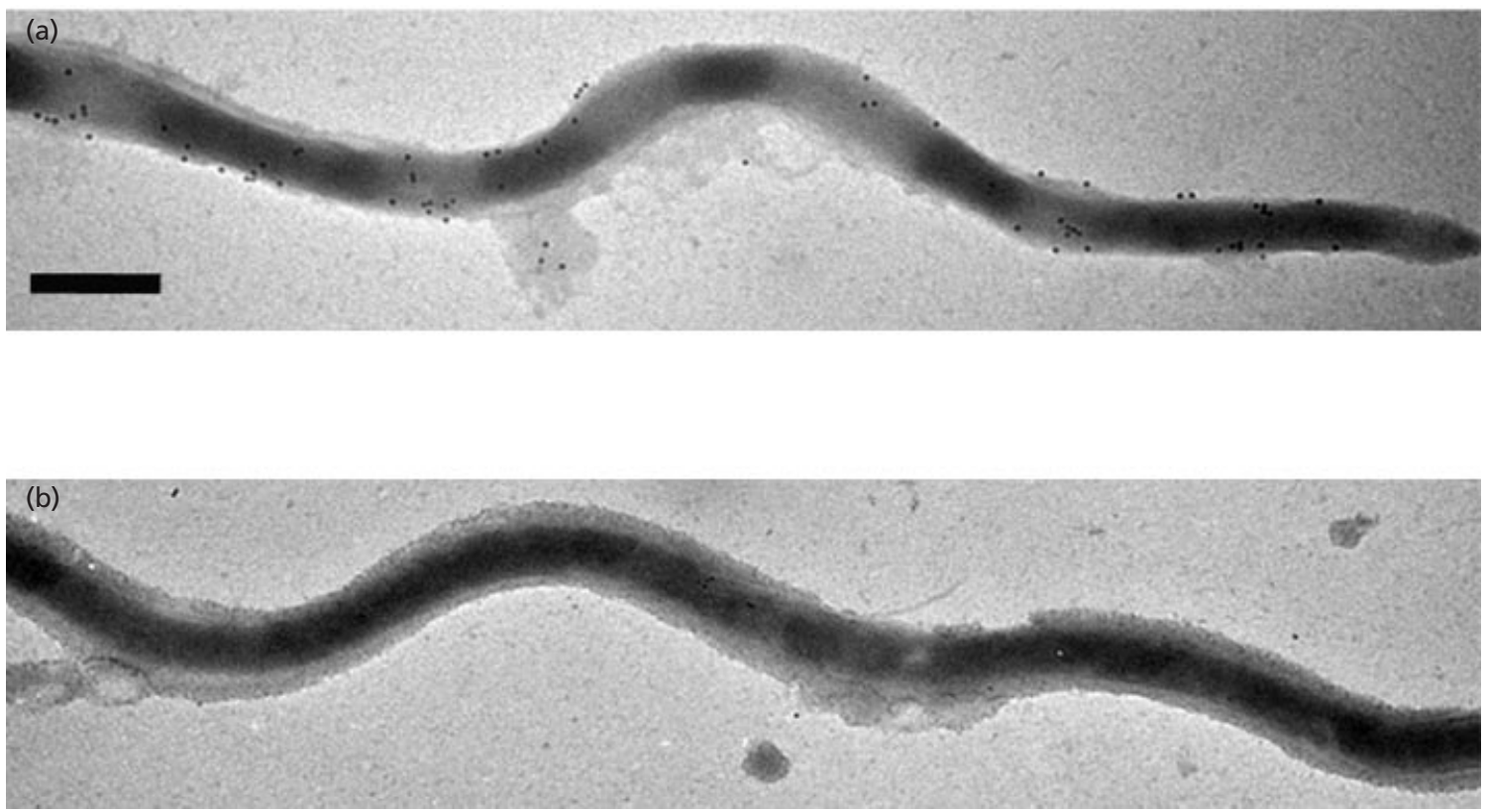

Fig. 4. Electron microscopic analyses of unfixed $B$. burgdorferi labelled with mAbs and gold bead-conjugated secondary antibody. (a) ErpA/l/N-specific mAb B11, (b) FlaB-specific mAb H9724. Bar, 0.5 $\mu \mathrm{m}$.

FlaB-specific mAb H9724 exhibited antibody binding, indicating that the outer membranes of the vast majority of examined bacteria remained intact during IFA processing. Additionally, no bacteria were detected by epifluorescence microscopy after incubation with only the fluorescence-tagged secondary antibody.

Similarly, electron microscopic analysis of unfixed bacteria incubated with mAb B11 and colloidal gold bead-conjugated secondary antibody demonstrated spirochaete labelling (Fig. 4). Control bacteria incubated with the anti-FlaB mAb H9724 were not labelled, indicating that the bacterial outer membranes were not damaged by this procedure, further proving that ErpA/ $\mathrm{I} / \mathrm{N}$ is exposed to the bacteria's outer environment.

\section{Growth inhibition by Erp-directed antibodies}

The IFA and immunogold experiments described above indicated that antibodies directed against Erp proteins can bind to intact bacteria. B. burgdorferi is often unable to grow in the presence of antibodies directed against surface-exposed proteins, which can cause the bacteria to form immobile clumps impaired for growth Bunikis \& Barbour, 1999; Cinco, 1992; Coleman et al., 1992; Hanson et al., 1998; Luke et al., 2000; Pavia et al., 1991; Sadziene et al., 1993). The reasons behind antibody-mediated growth inhibition are not well understood, but may be related to impaired nutrient acquisition. Such inhibition is not necessarily bacteriocidal, and complement is not required for growth 
Table 2. Growth inhibition by incubation with Erpdirected antibodies

\begin{tabular}{|lcc|}
\hline Antibody* & $\begin{array}{c}\text { Final medium } \\
\text { colour }\end{array}$ & $\begin{array}{c}\text { Immobile aggregate } \\
\text { formation } \neq\end{array}$ \\
\hline ErpA/I/N mAb & Red & + \\
ErpA/I/N mAb + & Yellow & - \\
$\mathrm{rErpA} / \mathrm{I} / \mathrm{N}$ & Red & + \\
ErpA/I/N pAb & Red & + \\
ErpB/J/O pAb & Red & + \\
ErpK pAb & Red & + \\
ErpL pAb & Red & + \\
ErpM pAb & Red & + \\
ErpP pAb & Red & + \\
ErpQ pAb & Red & + \\
ErpX pAb & Red & + \\
ErpY pAb & Yellow & - \\
FlaB mAb & Red & + \\
OspC mAb & Yellow & - \\
None & Yellow & - \\
Normal rabbit serum & Yellow & - \\
Unused hybridoma & Yellow & - \\
culture medium & Yellow & - \\
$\alpha-Y$ pestis LcrV pAb & M & \\
$\alpha$-Murine CD8 mAb & & \\
\hline
\end{tabular}

*pAb, polyclonal antibody.

† Determined after $72 \mathrm{~h}$ incubation. A change of the medium's phenol red indicator from red to yellow indicates bacterial growth (Sadziene et al., 1993).

$\neq$ Cultures were examined microscopically and scored for presence $(+)$ or absence $(-)$ of immobile bacterial aggregates.

impairment (Pavia et al., 1991; Sadziene et al., 1993). Some B. burgdorferi proteins are able to elicit protective immune responses in mammals and antibodies directed against such proteins tend to also inhibit bacterial growth in vitro (Hanson et al., 1998; Luke et al., 2000; Pavia et al., 1991; Sadziene et al., 1993).

Cultivation of B. burgdorferi in medium containing Erpdirected antibodies indicated that such antibodies can indeed inhibit bacterial growth. Addition of mAb B11, directed against ErpA/I/N, caused bacterial aggregation and inhibited growth (Table 2). This effect was specifically due to $\operatorname{ErpA} / \mathrm{I} / \mathrm{N}$ binding, since growth inhibition could be prevented by addition of recombinant $\operatorname{ErpA} / \mathrm{I} / \mathrm{N}$ protein at concentrations as low as $1.5 \mathrm{ng} \mathrm{ml}^{-1}$, the lowest level tested. Similar growth inhibition was also observed when cultivating bacteria in medium containing $\mathrm{mAb} \mathrm{B} 5$, directed against the outer surface protein OspC. No inhibition of growth was detected in control experiments with the FlaBdirected $\mathrm{mAb} \mathrm{H} 9724$, non-borrelial mAb 83-12-5 or unused hybridoma culture medium.

All polyclonal rabbit antisera also prevented bacterial growth, at dilutions up to $1: 5$ (Table 2). More dilute antisera did not appreciably affect growth. As noted above, some of the polyclonal antisera cross-reacted with other Erp proteins, so it is possible that in some cases aggregate formation was enhanced by antibodies binding to Erp proteins in addition to, or other than, the one being targeted. For example, antibodies raised against ErpB/J/O may have also interacted with ErpM, ErpQ and ErpX proteins, thus augmenting the formation of bacterial aggregates. Control experiments showed no inhibition of growth by normal rabbit serum or undiluted polyclonal rabbit antisera raised against a non-borrelial protein.

\section{DISCUSSION}

Studies of B. burgdorferi have indicated that the outer membranes of these bacteria can be damaged by treatments commonly used to study surface proteins of more typical Gram-negative bacteria. Since an earlier study used IFA binding to formaldehyde-fixed bacteria to examine Erp protein localization (Lam et al., 1994), we determined the cellular location of these proteins through several other methods that do not cause damage to the outer membrane. First, all examined B31 Erp proteins were susceptible to in situ digestion by proteases. Second, IFA binding to unfixed, unpermeabilized bacteria indicated that $\mathrm{mAb}$ B11 bound ErpA/I/N on the surface of B. burgdorferi. Third, similar results were obtained from immunogold labelling studies. Finally, Erp-directed antibodies, including an $\operatorname{ErpA} / \mathrm{I} / \mathrm{N}$-directed $\mathrm{mAb}$, caused formation of immobile bacterial aggregates. Taken together, these data greatly strengthen the earlier assertion that Erp proteins are located on the outer surface of B. burgdorferi (Lam et al., 1994).

Since mammals produce antibodies against Erp proteins within the first few weeks of infection (Akins et al., 1995; Das et al., 1997; Miller et al., 2000b; Nguyen et al., 1994; Stevenson et al., 1995, 1998a; Suk et al., 1995; Sung et al., 2000; Wallich et al., 1995), it is clear that Erps are made by the bacteria during that time and presumably perform a function(s) for the bacteria. The surface exposure of Erp proteins indicates that these proteins are positioned to interact with host cells, extracellular matrices, or other substances encountered by the bacteria during the natural infection cycle. An individual bacterium may contain many different Erp proteins, often with extensively variable sequences, which may permit the bacteria to interact with numerous host tissues. Alternatively, there are also conserved characteristics among Erp proteins, such as a high percentage of charged amino acid residues, that might permit Erps with different primary structures to interact with similar ligands (Stevenson et al., 2000b). Several B. burgdorferi proteins have been identified that bind specific host tissues (Coburn et al., 1999; Guo et al., 1995; Parveen \& Leong, 2000) and similar techniques might be adapted to search for substances that bind Erp proteins.

The ability of Erp-directed antibodies to prevent $B$. burgdorferi growth in vitro suggests that similar antibodies could protect animals against B. burgdorferi 
infection. Previous studies involving vaccination of mice with each of three Erp proteins, OspE or OspF of strain $\mathrm{N} 40$, or $\mathrm{pG}$ of strain ZS7, found either partial or no protection against bacterial challenges (Nguyen et al., 1994; Wallich et al., 1995). We have noted in the current study that antibodies from animals vaccinated with some Erp proteins also cross-reacted with other, similar Erp proteins, which could have contributed to the observed growth inhibition. Thus it may be possible that protection can be achieved by vaccination with an Erp that promotes cross-reactive antibody formation, or with a mixture of several different Erp proteins.

All B31 Erp proteins were sensitive to in situ treatment with at least one protease, with some Erps demonstrating resistance to digestion by certain enzymes (e.g. $\mathrm{ErpB} / \mathrm{J} / \mathrm{O}$ was uncleaved by proteinase K; Fig. 2). Since $B$. burgdorferi may be exposed to proteolytic enzymes during the bacterial infection cycle, resistance to proteases may be an important feature of borrelial surface proteins. There are several possible explanations for the ability of surface-exposed proteins to resist proteolysis. Although recombinant Erp proteins synthesized by E. coli and native proteins in Triton X100-treated B. burgdorferi were susceptible to the tested proteases, proteins of intact $B$. burgdorferi might be folded in different manners, such that protease recognition sites are hidden. Some surface proteins of the related spirochaete Borrelia turicatae are resistant to certain proteases, apparently due to their secondary structures (Zückert et al., 2001). Erp proteins in their native states may form multimers or interact with other membrane proteins that protect protease cleavage sites, similar to what has been postulated for the $B$. burgdorferi $\mathrm{p} 66$ (Oms66) and OspA proteins (Bunikis \& Barbour, 1999; Exner et al., 2000). While B. burgdorferi does not contain lipopolysaccharides identical to those of enteric Gram-negative bacteria (Takayama et al., 1987), borreliae and other spirochaetes contain nonproteinaceous membrane constituents that might serve similar functions (Beck et al., 1985; Cinco, 1992; Cinco et al., 1991; Eiffert et al., 1991; Schultz et al., 1998; Wheeler et al., 1993), and could interact with membrane proteins such as the Erps in manners that interfere with protease accessibility. Since a portion of ErpX molecules were not degraded by any of the protease treatments used in these studies, it is also possible that some Erps are located both on the bacterial outer surface and in the periplasmic space, as apparently are some other $B$. burgdorferi lipoproteins (Brusca et al., 1991; Cox et al., 1996; Radolf, 1994). Additionally, the insensitivity of $\mathrm{ErpB} / \mathrm{J} / \mathrm{O}$ and other proteins to digestion by proteolytic enzymes raises the possibility that the results of studies on other B. burgdorferi membrane proteins may be flawed in assigning subsurface localization based solely upon their inability to be degraded in situ.

While these studies demonstrated that Erp proteins are located on the $B$. burgdorferi outer surface, many additional questions about these proteins now must be answered. Why were some proteins, such as ErpQ and ErpX, resistant to in situ protease degradation? If Erps are protected from proteolysis by interactions with other surface components, what are they? If the reason behind partial resistance is that a fraction of those Erp protein molecules had subsurface locations, why were those unequally distributed while others, such as ErpA/ $\mathrm{I} / \mathrm{N}$ and ErpY, were completely localized to the outer surface? Do Erp proteins interact with host components, and if so, what are they? We are continuing studies to address these and other questions about the intriguing Erp proteins and their roles in the biology of $B$. burgdorferi and the pathogenesis of Lyme disease.

\section{NOTE ADDED IN PROOF}

A possible function for Erp proteins is suggested by a recent finding that at least one Erp, the OspE protein of strain N40, can bind complement regulatory factor $\mathrm{H}$ (Hellwage et al., 2001).

\section{ACKNOWLEDGEMENTS}

This research was funded by US Public Health Service grant RO1-AI44254 and University of Kentucky Chandler Medical Center Research Fund grant 949 to Brian Stevenson.

We thank Don Cohen, Jerry Woodward, Tom Schwan, Susan Straley, Chris Wulff-Strobel and Ela Skrzypek for providing antibodies and for assistance with IFAs, Julie Stewart for technical assistance, Jeff Hopkins for assistance in producing recombinant Erp proteins, Ralph Larsen and Patti Rosa for assistance with raising rabbit antisera, and Gary Hettrick for graphics assistance.

\section{REFERENCES}

Akins, D. R., Porcella, S. F., Popova, T. G., Shevchenko, D., Baker, S. I., Li, M., Norgard, M. V. \& Radolf, J. D. (1995). Evidence for in vivo but not in vitro expression of a Borrelia burgdorferi outer surface protein F (OspF) homologue. Mol Microbiol 18, 507-520.

Akins, D. R., Bourell, K. W., Caimano, M. J., Norgard, M. V. \& Radolf, J. D. (1998). A new animal model for studying Lyme disease spirochetes in a mammalian host-adapted state. J Clin Invest 101, 2240-2250.

Anguita, J., Samanta, S., Revilla, B., Suk, K., Das, S., Barthold, S. W. \& Fikrig, E. (2000). Borrelia burgdorferi gene expression in vivo and spirochete pathogenicity. Infect Immun 68, 1222-1230.

Barbour, A. G. (1984). Isolation and cultivation of Lyme disease spirochetes. Yale J Biol Med 57, 521-525.

Barbour, A. G. \& Hayes, S. F. (1986). Biology of Borrelia species. Microbiol Rev 50, 381-400.

Barbour, A. G., Tessier, S. L. \& Todd, W. J. (1983b). Lyme disease spirochetes and ixodid tick spirochetes share a common surface antigenic determinant defined by a monoclonal antibody. Infect Immun 41, 795-804.

Barbour, A. G., Burgdorfer, W., Hayes, S. F., Peter, O. \& Aeschlimann, A. (1983b). Isolation of a cultivable spirochete from Ixodes ricinus ticks of Switzerland. Curr Microbiol 8, 123-126.

Barbour, A. G., Hayes, S. F., Heiland, R. A., Schrumpf, M. E. \& Tessier, S. L. (1986). A Borrelia-specific monoclonal antibody binds to a flagellar epitope. Infect Immun 52, 549-554. 
Beck, G., Habicht, G. S., Benach, J. L. \& Coleman, J. L. (1985). Chemical and biologic characterization of a lipopolysaccharide extracted from the Lyme disease spirochete (Borrelia burgdorferi). J Infect Dis 152, 108-117.

Bledsoe, H. A., Carroll, J. A., Whelchel, T. R., Farmer, M. A., Dorward, D. W. \& Gherardini, F. C. (1994). Isolation and partial characterization of Borrelia burgdorferi inner and outer membranes by using isopycnic centrifugation. J Bacteriol 176, 7447-7455.

Bono, J. L., Tilly, K., Stevenson, B., Hogan, D. \& Rosa, P. (1998). Oligopeptide permease in Borrelia burgdorferi: putative peptidebinding components encoded by both chromosomal and plasmid loci. Microbiology 144, 1033-1044.

Bono, J. L., Elias, A. F., Kupko, J. J., Stevenson, B., Tilly, K. \& Rosa, P. (2000). Efficient targeted mutagenesis in Borrelia burgdorferi. J Bacteriol 182, 2445-2452.

Brusca, J. S., McDowall, A. W., Norgard, M. V. \& Radolf, J. D. (1991). Localization of outer surface proteins A and B in both the outer membrane and intracellular compartments of Borrelia burgdorferi. J Bacteriol 173, 8004-8008.

Bunikis, J. \& Barbour, A. G. (1999). Access of antibody or trypsin to an integral outer membrane protein (P66) of Borrelia burgdorferi is hindered by Osp lipoproteins. Infect Immun 67, 2874-2883.

Burgdorfer, W., Barbour, A. G., Hayes, S. F., Benach, J. L., Grunwaldt, E. \& Davis, J. P. (1982). Lyme disease - a tick-borne spirochetosis? Science 216, 1317-1319.

Casjens, S., van Vugt, R., Tilly, K., Rosa, P. A. \& Stevenson, B. (1997). Homology throughout the multiple 32-kilobase circular plasmids present in Lyme disease spirochetes. J Bacteriol 179, 217-227.

Casjens, S., Palmer, N., van Vugt, R. \& 12 other authors (2000). A bacterial genome in flux: the twelve linear and nine circular extrachromosomal DNAs of an infectious isolate of the Lyme disease spirochete Borrelia burgdorferi. Mol Microbiol 35, 490-516.

Cinco, M. (1992). Selection of a Borrelia burgdorferi antigenic variant by cultivation in the presence of increasing amounts of homologous immune serum. FEMS Microbiol Lett 92, 15-18.

Cinco, M., Banfi, E., Balanzin, D., Godeas, C. \& Panfili, E. (1991). Evidence for (lipo)oligosaccharides in Borrelia burgdorferi and their serological specificity. FEMS Microbiol Lett 76, 33-38.

Coburn, J., Chege, W., Magoun, L., Bodary, S. C. \& Leong, J. M. (1999). Characterization of a candidate Borrelia burgdorferi $\beta 3$ chain integrin ligand identified using a phage display library. Mol Microbiol 34, 926-940.

Coleman, J. L., Rogers, R. C. \& Benach, J. L. (1992). Selection of an escape variant of Borrelia burgdorferi by use of bacteriocidal monoclonal antibodies to OspB. Infect Immun 60, 3098-3104.

Cox, D. L., Akins, D. R., Bourell, K. W., Lahdenne, P., Norgard, M. V. \& Radolf, J. D. (1996). Limited surface exposure of Borrelia burgdorferi outer surface lipoproteins. Proc Natl Acad Sci US A 93, 7973-7978.

Cunningham, T. M., Thomas, D. D., Thompson, S. D., Miller, J. N. \& Lovett, M. A. (1988). Identification of Borrelia burgdorferi surface components by Triton X-114 phase partitioning. Ann N Y Acad Sci 539, 376-378.

Das, S., Barthold, S. W., Stocker Giles, S., Montgomery, R. R., Telford, S. R. \& Fikrig, E. (1997). Temporal pattern of Borrelia burgdorferi $p 21$ expression in ticks and the mammalian host. $J$ Clin Invest 99, 987-995.
Dunn, J. J., Lade, B. N. \& Barbour, A. G. (1990). Outer surface protein A (OspA) from the Lyme disease spirochete, Borrelia burgdorferi: high level expression and purification of a soluble recombinant form of OspA. Protein Expr Purif 1, 159-168.

Eiffert, H., Lotter, H., Jarecki-Khan, K. \& Thomssen, R. (1991). Identification of an immunreactive non-proteinaceous component in Borrelia burgdorferi. Med Microbiol Immunol 180, 229-237.

El-Hage, N., Lieto, L. D. \& Stevenson, B. (1999). Stability of erp loci during Borrelia burgdorferi infection: recombination is not required for chronic infection of immunocompetent mice. Infect Immun 67, 3146-3150.

Exner, M. M., Wu, X., Blanco, D. R., Miller, J. N. \& Lovett, M. A. (2000). Protection elicited by native outer membrane protein Oms66 (p66) against host-adapted Borrelia burgdorferi: conformational nature of bacteriocidal epitopes. Infect Immun 68, 2647-2654.

Fuchs, R., Jauris, S., Lottspeich, F., Preac-Mursic, V., Wilske, B. \& Soutschek, E. (1992). Molecular analysis and expression of a Borrelia burgdorferi gene encoding a $22 \mathrm{kDa}$ protein $(\mathrm{pC})$ in Escherichia coli. Mol Microbiol 6, 503-509.

Gilmore, R. D., Jr \& Mbow, M. L. (1998). A monoclonal antibody generated by antigen inoculation via tick bite is reactive to the Borrelia burgdorferi Rev protein, a member of the 2.9 gene family locus. Infect Immun 66, 980-986.

Gilmore, R. D., Jr \& Mbow, M. L. (1999). Conformational nature of the Borrelia burgdorferi $\mathrm{B} 31$ outer surface protein $\mathrm{C}$ protective epitope. Infect Immun 67, 5463-5469.

Guo, B. P., Norris, S. J., Rosenberg, L. C. \& Höök, M. (1995). Adherence of Borrelia burgdorferi to the proteoglycan decorin. Infect Immun 63, 3467-3472.

Haake, D. A. (2000). Spirochaetal lipoproteins and pathogenesis. Microbiology 146, 1491-1504.

Hanson, M. S., Cassatt, D. R., Guo, B. P., Patel, N. K., McCarthy, M. P., Dorward, D. W. \& Höök, M. (1998). Active and passive immunity against Borrelia burgdorferi decorin binding protein A (DbpA) protects against infection. Infect Immun 66, 2143-2153.

Hellwage, J., Meri, T., Heikkilä, T., Alitalo, A., Panelius, J., Lahdenne, P., Seppälä, I. J. T. \& Meri, S. (2001). The complement regulatory factor $\mathrm{H}$ binds to the surface protein OspE of Borrelia burgdorferi. J Biol Chem 276 (in press).

Holt, S. C. (1978). Anatomy and chemistry of spirochetes. Microbiol Rev 42, 114-160.

Jones, J. D., Bourell, K. W., Norgard, M. V. \& Radolf, J. D. (1995). Membrane topology of Borrelia burgdorferi and Treponema pallidum lipoproteins. Infect Immun 63, 2424-2434.

Lam, T. T., Nguyen, T.-P. K., Montgomery, R. R., Kantor, F. S., Fikrig, E. \& Flavell, R. A. (1994). Outer surface proteins E and F of Borrelia burgdorferi, the agent of Lyme disease. Infect Immun 62, 290-298.

Luft, B. J., Jiang, W., Munoz, P., Dattwyler, R. J. \& Gorevic, P. D. (1989). Biochemical and immunological characterization of the surface proteins of Borrelia burgdorferi. Infect Immun 57, 3637-3645.

Luke, C. J., Marshall, M. A., Zahradnik, J. M., Bybel, M., Menefee, B. E. \& Barbour, A. G. (2000). Growth-inhibiting antibody responses of humans vaccinated with recombinant outer surface protein A or infected with Borrelia burgdorferi or both. J Infect Dis 181, 1062-1068.

Marconi, R. T., Sung, S. Y., Norton Hughes, C. A. \& Carlyon, J. A. (1996). Molecular and evolutionary analyses of a variable series of genes in Borrelia burgdorferi that are related to ospE and ospF, 
constitute a gene family, and share a common upstream homology box. J Bacteriol 178, 5615-5626.

Mathiesen, M. J., Holm, A., Christiansen, M., Blom, J., Hansen, K., Østergaard, S. \& Theisen, M. (1998). The dominant epitope of Borrelia garinii outer surface protein $\mathrm{C}$ recognized by sera from patients with neuroborreliosis has a surface-exposed conserved structural motif. Infect Immun 66, 4073-4079.

Mbow, M. L., Gilmore, R. D., Jr \& Titus, R. G. (1999). An OspCspecific monoclonal antibody passively protects mice from ticktransmitted infection by Borrelia burgdorferi B31. Infect Immun 67, 5470-5472.

Miller, J. C., Bono, J. L., Babb, K., El-Hage, N., Casjens, S. \& Stevenson, B. (2000a). A second allele of eppA in Borrelia burgdorferi strain B31 is located on the previously undetected circular plasmid cp9-2. J Bacteriol 182, 6254-6258.

Miller, J. C., El-Hage, N., Babb, K. \& Stevenson, B. (2000b). Borrelia burgdorferi B31 Erp proteins that are dominant immunoblot antigens of animals infected with isolate B31 are recognized by only a subset of human Lyme disease patient sera. J Clin Microbiol 38, 1569-1574.

Nguyen, T.-P. K., Lam, T. T., Barthold, S. W., Telford, S. R., Flavell, R. A. \& Fikrig, E. (1994). Partial destruction of Borrelia burgdorferi within ticks that engorged on OspE- or OspF-immunized mice. Infect Immun 62, 2079-2084.

Parveen, N. \& Leong, J. M. (2000). Identification of a candidate glycosaminoglycan-binding adhesin of the Lyme disease spirochete Borrelia burgdorferi. Mol Microbiol 35, 1220-1234.

Pavia, C. S., Kissel, V., Bittker, S., Cabello, F. \& Levine, S. (1991). Antiborrelial activity of serum from rats injected with the Lyme disease spirochete. J Infect Dis 163, 656-659.

Radolf, J. D. (1994). Role of outer membrane architecture in immune evasion by Treponema pallidum and Borrelia burgdorferi. Trends Microbiol 2, 307-311.

Radolf, J. D., Bourell, K. W., Akins, D. R., Brusca, J. S. \& Norgard, M. V. (1994). Analysis of Borrelia burgdorferi membrane architecture by freeze-fracture electron microscopy. J Bacteriol 176, 21-31.

Radolf, J. D., Goldberg, M. S., Bourell, K., Baker, S. I., Jones, J. D. \& Norgard, M. V. (1995). Characterization of outer membranes isolated from Borrelia burgdorferi, the Lyme disease spirochete. Infect Immun 63, 2154-2163.

Sadziene, A., Thompson, P. A. \& Barbour, A. G. (1993). In vitro inhibition of Borrelia burgdorferi growth by antibodies. J Infect Dis 167, 165-172.

Schultz, C. P., Wolf, V., Lange, R., Mertens, E., Wecke, J., Naumann, D. \& Zähringer, U. (1998). Evidence for a new type of outer membrane lipid in oral spirochete Treponema denticola. J Biol Chem 273, 15661-15666.

Schwan, T. G., Piesman, J., Golde, W. T., Dolan, M. C. \& Rosa, P. A. (1995). Induction of an outer surface protein on Borrelia burgdorferi during tick feeding. Proc Natl Acad Sci US A 92, 2909-2913.

Schwan, T. G., Burgdorfer, W. \& Rosa, P. A. (1999). Borrelia. In Manual of Clinical Microbiology, pp. 746-758. Edited by P. R.
Murray, E. J. Baron, M. A. Pfaller, F. C. Tenover \& R. H. Yolken. Washington, DC: American Society for Microbiology.

Stevenson, B., Schwan, T. G. \& Rosa, P. A. (1995). Temperaturerelated differential expression of antigens in the Lyme disease spirochete, Borrelia burgdorferi. Infect Immun 63, 4535-4539.

Stevenson, B., Tilly, K. \& Rosa, P. A. (1996). A family of genes located on four separate 32-kilobase circular plasmids in Borrelia burgdorferi B31. J Bacteriol 178, 3508-3516.

Stevenson, B., Bono, J. L., Schwan, T. G. \& Rosa, P. (1998a). Borrelia burgdorferi Erp proteins are immunogenic in mammals infected by tick bite, and their synthesis is inducible in cultured bacteria. Infect Immun 66, 2648-2654.

Stevenson, B., Casjens, S. \& Rosa, P. (1998b). Evidence of past recombination events among the genes encoding the Erp antigens of Borrelia burgdorferi. Microbiology 144, 1869-1879.

Stevenson, B., Porcella, S. F., Oie, K. L., Fitzpatrick, C. A., Raffel, S. J., Lubke, L., Schrumpf, M. E. \& Schwan, T. G. (2000a). The relapsing fever spirochete Borrelia hermsii contains multiple, antigen-encoding circular plasmids that are homologous to the cp32 plasmids of Lyme disease spirochetes. Infect Immun 68, 3900-3908.

Stevenson, B., Zückert, W. R. \& Akins, D. R. (2000b). Repetition, conservation, and variation: the multiple cp32 plasmids of Borrelia species. J Mol Microbiol Biotechnol 2, 411-422.

Suk, K., Das, S., Sun, W., Jwang, B., Barthold, S. W., Flavell, R. A. \& Fikrig, E. (1995). Borrelia burgdorferi genes selectively expressed in the infected host. Proc Natl Acad Sci U S A 92, 4269-4273.

Sung, S. Y., McDowell, J. V., Carlyon, J. A. \& Marconi, R. T. (2000). Mutation and recombination in the upstream homology boxflanked ospE-related genes of the Lyme disease spirochetes result in the development of new antigenic variants during infection. Infect Immun 68, 1319-1327.

Takayama, K., Rothenberg, R. J. \& Barbour, A. G. (1987). Absence of lipopolysaccharide in the Lyme disease spirochete, Borrelia burgdorferi. Infect Immun 55, 2311-2313.

Wallich, R., Brenner, C., Kramer, M. D. \& Simon, M. M. (1995). Molecular cloning and immunological characterization of a novel linear-plasmid-encoded gene, $p G$, of Borrelia burgdorferi expressed only in vivo. Infect Immun 63, 3327-3335.

Wheeler, C. M., Monco, J. C. G., Benach, J. L., Golightly, M. G., Habicht, G. S. \& Steere, A. C. (1993). Nonprotein antigens of Borrelia burgdorferi. J Infect Dis 167, 665-674.

Wilske, B., Preac-Mursic, V., Jauris, S., Hofmann, A., Pradel, I., Soutschek, E., Schwab, E., Will, G. \& Wanner, G. (1993). Immunological and molecular polymorphisms of OspC, an immunodominant major outer surface protein of Borrelia burgdorferi. Infect Immun 61, 2182-2191.

Zückert, W. R., Kerentseva, T. A., Lawson, C. L. \& Barbour, A. G. (2001). Structure analysis of the neurotropism-associated Borrelia turicatae VspA lipoprotein. J Biol Chem 276, 457-463.

Received 12 September 2000; revised 27 November 2000; accepted 15 December 2000 